Hind T Jarjees

BDS, MSc (Assist Lect)

Khawla M Awni

BDS, MSc (Assist Lect)

Younis MS Hasan

BDS, MSc (Assist Lect)

\section{Validation of Tanaka and Johnston Me- thod on Iraqi Population}

\author{
Dept of Pedod, orthod, and Prev Dentistry \\ College of Dentistry, University of Mosul
}

\begin{abstract}
Aims: To validate Tanaka and Johnston's analysis on (50) Iraqi patients (29 females and 21 males) aged 14-22 years. The patients had normal class I molar relation ship with full permanent dentition. Materials and Methods: Plaster models of 50 (14-22) years old patients were selected. Mesio-distal crown diameter for maxillary and mandibular permanent teeth were measured. Statistical descriptive, probability theory, correlation coefficients between individual and grouped teeth were calculated using Tanaka and Johnston method. Results: Tanaka and Johnston's analysis tables, equations and approximations were modified in order to improve the accuracy of the prediction. The correlation coefficients found between the size of the permanent mandibular central incisors and maxillary first molars $(1,1,6$ and 6) and maxillary and mandibular canines and premolars were high $(r=0.62$ and $r=0.67$, respectively). New, more accurate prediction tables applicable at earlier ages, and new regression equations were constructed. In addition, new easier approximations were developed to allow the prediction of the size of the unerupted maxillary canines and premolars by adding $5.6 \mathrm{~mm}$ to the half-widths of teeth 1 , 1,6 and 6 . The analogous prediction of the size of unerupted mandibular canines and premolars was obtained by adding $5.4 \mathrm{~mm}$ to the half widths of same teeth $1,1,6$ and 6 . Conclusions: The new analysis prediction tables and new regression equations based on teeth $1,1,6$ and 6 , which erupt earlier than teeth used by Tanaka and Johnston, proved even more accurate than both previous equations.

Key Words: Prediction Analysis, regression equation, unerupted teeth.
\end{abstract}

Jarjees HT, Awni KHM, Hasan YMS. Validation of Tanaka and Johnston Method on Iraqi population. Al-Rafidain Dent J. 2009; 9(1): 17-23.

Received: $12 / 11 / 2007 \quad$ Sent to Referees: $12 / 11 / 2007$

Accepted for Publication: 3/2/2008

\section{INTRODUCTION}

Mixed dentition analysis is the prediction of mesio-distal diameters (MDD) of unerupted canine and premolars (C, P1, $\mathrm{P2}$ ) to determine the discrepancy between the available and required space in each dental arch ${ }^{(1)}$. One way for clinicians to get a better feel for the clinical significance of a discrepancy is to focus more on the actual size of the discrepancy than on the Bolton ratios alone ${ }^{(2)}$. An accurate prediction can help answer the traditional question of whether the available space in the posterior segments is sufficient to allow the permanent teeth to erupt freely with good alignment in their respective arches ${ }^{(3)}$.

There are many basic methods of predicting MDD of unerupted $\mathrm{C}, \mathrm{P} 1$ and P2: application of middle values, correlationstatistical methods, combination of X-ray and correlation-statistical methods and from $45^{\circ}$ oblique teleradiograph ${ }^{(4-7)}$. Because of their simplicity, correlationstatistical methods are most frequently applied $^{(8-10)}$.

The Tanaka and Johnston analysis has shown that it over estimates the MDD of unerupted C,P1 and P2 in the majority of cases when used in Syrian or other Arabian populations ${ }^{(8)}$. Several simple linear regression equations have been proposed for populations of different ethnic origins $(8,10-15)$.

Nourallah et al., ${ }^{(16)}$ reported that the sum of the lower central incisor and upper first molars have the highest predicted value (determination coefficient between 
$52 \%$ and 56\%) for MDD of unerupted C, P1 and P2. A year later, Legovic et al., ${ }^{(4)}$ developed multiple linear regression equations (MLRE) with higher predicted values (determination coefficient between 62\% and $72 \%$ ) where they also considered the bucco-lingual tooth size. Recently, Hashim and Al-Shalan ${ }^{(17)}$ have reported the inclusion of sex factors. While, Bernabe et al., ${ }^{(18)}$ proposed several single linear regression equations (SLRE) on the basis of the sexual dimorphism in tooth size that predominated in their sample.

This study was designed to examine the accuracy of Tanaka and Johnston's (11) analysis on Iraqi population and to attempt to find a more accurate formula for predicting the MDD of C, P1 and P2 for Iraqi population.

\section{MATERIALS AND METHODS}

Plaster models of 50 (14-22) years old patients (29 females and 21 males) were selected from Orthodontic Department, College of Dentistry at Mosul University. All patients had relevant teeth fully erupted and represented with no proximal caries or fillings, morphological anomalies, missing teeth, proximal or occlusal abrasion or bruxism. A pointed Vernier Caliper (Dental Vernier, Dentaurum) was used to measure MDD of all teeth from mesial contact point to distal contact point according to the method described by Moorrees et al ${ }^{(19)}$. The data were analyzed using statistical package for social statis- tics (SPSS), statistical descriptives; means, minimum, maximum, range and standard deviation were calculated. Applying the probability theory, the teeth were divided into more than 100 possible groups. Table (1) shows the four most important groups. Correlation coefficients between individual and grouped teeth were calculated and confidence intervals ${ }^{(20)}$ were constructed according to Tanaka and Johnston. Finally, new equations were developed to optimize the Tanaka and Johnston's analysis. The accuracy of these new equations were tested on a sample, and the results were compared with those of Tanaka and Johns$\operatorname{ton}^{(11)}$.

\section{RESULTS}

Correlation coefficients were calculated between the teeth groups as presented in Table (1) and were remarkable in group Three and Four, which can be used to establish regression equations. Although other high values were also found, they can't be used in regression because of local complicating factors such as distal gingival coverage as late eruption (e.g. lower first permanent molars) or morphological drawbacks such as a deformity of the maxillary lateral permanent incisor. The correlation coefficients for group Three differ from those in Tanaka and Johnston's study and require modification using the equations. The correlation coefficients for group Four were higher and are used here as a base for establishing new equations.

Table (1): The highest correlation coefficients of tooth groups by tooth type and gender.

\begin{tabular}{|c|c|c|c|c|c|c|c|}
\hline \multirow{2}{*}{ Group } & \multirow{2}{*}{$\begin{array}{l}\text { Tooth } \\
\text { Group }\end{array}$} & \multicolumn{3}{|c|}{$\begin{array}{l}\text { Maxillary } \\
\text { C, P1, P2 }\end{array}$} & \multicolumn{3}{|c|}{$\begin{array}{c}\text { Mandibular } \\
\text { C, P1, P2 }\end{array}$} \\
\hline & & $\underset{(r)}{\text { Male }}$ & $\begin{array}{c}\text { Female } \\
(r)\end{array}$ & $\begin{array}{c}\text { Total } \\
(r)\end{array}$ & $\begin{array}{c}\text { Male } \\
(r)\end{array}$ & $\begin{array}{c}\text { Female } \\
(r)\end{array}$ & $\begin{array}{c}\text { Total } \\
(r)\end{array}$ \\
\hline 1 & 1,1 & 0.67 & 0.38 & 0.57 & 0.61 & 0.50 & 0.60 \\
\hline 2 & $\underline{6,6}$ & 0.78 & 0.26 & 0.58 & 0.61 & 0.27 & 0.49 \\
\hline 3 & $1,2,1,2$ & 0.60 & 0.43 & 0.57 & 0.55 & 0.54 & 0.59 \\
\hline 4 & $1,1,6,6$ & 0.82 & 0.38 & 0.67 & 0.67 & 0.45 & 0.62 \\
\hline
\end{tabular}

r: indicates correlation coefficient. All measurements in millimeters. 
The confidence intervals were calculated and sorted into prediction table as shown in Table (2), by which the sizes of unerupted teeth can be predicted at different levels of confidence by using the widths of the four mandibular permanent incisors. The confidence level of $75 \%$ was utilized to constrict a simple form of regression equations: $\mathrm{Y}=\mathrm{A}+\mathrm{B}(\mathrm{X})$, where $\mathrm{Y}$ equals the predicted sizes of canines and premolars, A and B are the equation's constants, and $\mathrm{X}$ is defined as the sum of widths of the four mandibular incisors. According to our analysis, the regression equation was: $\mathrm{Y}=9.95+0.50(\mathrm{X})$ for the maxilla, and $\mathrm{Y}=10.15+0.48(\mathrm{X})$ for the mandible. The standard error of the estimated values (SEE) was 1.12 for the max- illary equations and 1.05 for the mandibular equations. To predict the sizes of unerupted C, P1 and P2 in the mixed dentition of maxillary teeth, a simple approximation was established by adding $9.8 \mathrm{~mm}$ to half the widths of the four mandibular permanent incisors, and by adding $9.7 \mathrm{~mm}$ to the same teeth to predict the sizes of mandibular C, P1 and P2. The new analysis equations that involve a strong correlation between the sizes of mandibular central permanent incisors and maxillary first permanent molars and the MDD of unerupted C, P1 and P2 in both jaws (maxilla $r=0.62$; mandible $r=0.67$, Table 1 ) calls for new modified and more accurate equations based on the use of different teeth as an index.

Table (2): Probability of predicting the sizes of unerupted C, P1, P2 from the sum of widths of the four mandibular permanent incisors.

Sum of MDD of the Four Mandibular Permanent Incisors

\begin{tabular}{|c|c|c|c|c|c|c|c|c|c|c|}
\hline $\mathrm{Cl}^{*}$ & 20.5 & 21 & 21.5 & 22 & 22.5 & 23 & 23.5 & 24 & 24.5 & 25 \\
\hline $95 \%$ & 20.40 & 21.00 & 21.40 & 22.00 & 22.40 & 23.00 & 23.20 & 24.00 & 24.00 & 24.73 \\
\hline $85 \%$ & 20.40 & 21.00 & 21.20 & 22.00 & 22.20 & 22.89 & 23.00 & 23.30 & 23.64 & 24.00 \\
\hline $75 \%$ & 20.40 & 21.00 & 21.00 & 22.00 & 22.00 & 22.40 & 22.45 & 23.00 & 23.00 & 23.15 \\
\hline $65 \%$ & 20.40 & 20.78 & 21.00 & 21.60 & 22.00 & 22.01 & 22.20 & 22.45 & 22.58 & 22.97 \\
\hline $50 \%$ & 20.40 & 20.60 & 20.60 & 21.10 & 21.40 & 22.00 & 22.00 & 22.00 & 22.00 & 22.10 \\
\hline $35 \%$ & 19.85 & 20.51 & 20.60 & 20.90 & 21.00 & 21.19 & 21.20 & 21.55 & 21.60 & 21.66 \\
\hline $25 \%$ & 19.55 & 20.40 & 20.40 & 20.60 & 20.60 & 21.00 & 21.00 & 21.00 & 21.00 & 21.05 \\
\hline $15 \%$ & 19.40 & 19.97 & 20.16 & 20.40 & 20.50 & 20.60 & 20.60 & 21.60 & 20.60 & 20.60 \\
\hline $5 \%$ & 19.40 & 19.40 & 19.40 & 19.55 & 19.70 & 19.91 & 19.97 & 20.10 & 20.12 & 20.18 \\
\hline
\end{tabular}

*Cl: indicates confidence intervals. All measurements in millimeters.

As in Tanaka and Johnston's study ${ }^{(11)}$, confidence intervals were calculated and 
sorted into prediction table as demonstrated in Table (3). The confidence level of $75 \%$ was used to construct an uncomplicated form of the equation: $Y^{\prime}=A^{\prime}+B^{\prime}\left(X^{\prime}\right)$, where $Y^{\prime}$ equals the predicted size of $\mathrm{C}, \mathrm{P} 1$ and $\mathrm{P} 2, \mathrm{~A}^{\prime}+\mathrm{B}^{\prime}$ are the equation's constants, and $\mathrm{X}^{\prime}$ is defined by sum of widths of mandibular central permanent incisors and maxillary first permanent molars. The equation is: $\mathrm{Y}^{\prime}=$ $4.81+0.52\left(\mathrm{X}^{\prime}\right)$ for the maxilla, and $\mathrm{Y}^{\prime}=$ $6.78+0.46\left(X^{\prime}\right)$ for the mandible. The standard error of the estimated values (SEE) was 1.02 for the maxillary equations and 1.01 for the mandibular equations, which means that the accuracy of the new analy- sis is higher than that of Tanaka and Johnston. It also shows that the modification we did, applies to our population since it shows the lowest standard errors.

A simple approximation was established to predict the MDD of unerupted C, $\mathrm{P} 1$ and $\mathrm{P} 2$ in the mixed dentition for maxillary teeth by adding $5.6 \mathrm{~mm}$ to the half of the widths of mandibular permanent central incisors and maxillary first permanent molars. The analogous value for sizes of the unerupted mandibular C, P1 and P2 in the mixed dentition can be obtained by adding $5.4 \mathrm{~mm}$ to half the widths of the same mandibular central permanent incisors and maxillary first permanent molars.

Table (3): Probability of predicting the sizes of uUnerupted C, P1, P2 from the sum of MDD of the mandibular central permanent incisors and maxillary first permanent molars.

Sum of MDD of Mandibular Central Permanent Incisors and Maxillary First Permanent Molars

\begin{tabular}{|c|c|c|c|c|c|c|c|c|c|c|c|c|}
\hline $\mathrm{Cl}^{*}$ & 28.5 & 29 & 29.5 & 30 & 30.5 & 31 & 31.5 & 32 & 32.5 & 33 & 33.5 & 34 \\
\hline $95 \%$ & 28.20 & 28.80 & 29.40 & 30.00 & 30.40 & 31.00 & 31.40 & 32.00 & 32.38 & 32.75 & 32.94 & 33.91 \\
\hline $85 \%$ & 28.20 & 28.80 & 29.40 & 30.00 & 30.22 & 31.00 & 31.00 & 31.80 & 31.94 & 32.05 & 32.22 & 32.53 \\
\hline $75 \%$ & 28.15 & 28.50 & 29.30 & 30.00 & 30.00 & 30.60 & 31.00 & 31.10 & 31.60 & 31.80 & 31.80 & 32.00 \\
\hline $65 \%$ & 28.05 & 28.18 & 29.20 & 29.80 & 30.00 & 30.20 & 30.40 & 31.00 & 31.00 & 31.10 & 31.36 & 31.74 \\
\hline $50 \%$ & 28.00 & 28.00 & 28.80 & 29.60 & 29.60 & 30.00 & 30.00 & 30.20 & 30.40 & 30.60 & 30.80 & 31.00 \\
\hline $35 \%$ & 27.90 & 28.00 & 28.10 & 29.20 & 29.40 & 29.60 & 29.60 & 29.93 & 30.00 & 30.00 & 30.00 & 30.00 \\
\hline $25 \%$ & 27.70 & 27.80 & 28.00 & 28.80 & 29.10 & 29.30 & 29.40 & 29.55 & 29.60 & 29.60 & 29.60 & 29.65 \\
\hline $15 \%$ & 27.60 & 27.60 & 27.80 & 28.00 & 28.09 & 28.50 & 28.68 & 29.14 & 29.20 & 29.20 & 29.20 & 29.27 \\
\hline $5 \%$ & 27.60 & 27.60 & 27.60 & 27.60 & 27.66 & 27.80 & 27.84 & 27.98 & 28.00 & 28.00 & 28.09 & 28.00 \\
\hline
\end{tabular}

\section{DISCUSSION}

The Tanaka and Johnston's Analysis of 50 Iraqi people results in lower correlation coefficients (maxilla $\mathrm{r}=0.59$, mandible $r=0.57$ ) than other analysis when us- ing maxillary permanent first molars (maxilla $r=0.62$, mandible $r=0.67$ ).

This agreed with Nourallah et al., ${ }^{(16)}$ study on Syrian population in which the correlation coefficients (maxilla $\mathrm{r}=0.67$, 
mandible $r=0.68)$ were higher than Tanaka and Johnston's study (maxilla $\mathrm{r}=$
0.63 , mandible $r=0.65$ ) as presented in Table (4).

Table (4): Comparison of Correlation Coefficients, Regression Coefficients and Standard Errors between Tanaka and Johnston, Nourallah et al, Present Study and Present Modified Study.

\begin{tabular}{|c|c|c|c|c|}
\hline & & & \multicolumn{2}{|c|}{ Canine and Premolar } \\
\hline & & & Maxilla & Mandible \\
\hline \multirow{4}{*}{$\begin{array}{l}\text { Correlation } \\
\text { Coefficient }\end{array}$} & & 1 & 0.63 & 0.65 \\
\hline & & 2 & 0.67 & 0.68 \\
\hline & & 3 & 0.59 & 0.57 \\
\hline & & 4 & 0.62 & 0.67 \\
\hline \multirow{8}{*}{$\begin{array}{l}\text { Regression } \\
\text { Coefficients }\end{array}$} & \multirow{6}{*}{ A } & 1 & 10.4 & 9.18 \\
\hline & & 2 & 9.87 & 9.32 \\
\hline & & 3 & 9.95 & 10.15 \\
\hline & & 4 & 4.18 & 6.78 \\
\hline & & 1 & 0.51 & 0.54 \\
\hline & & 2 & 0.50 & 0.55 \\
\hline & \multirow{2}{*}{$\mathbf{B}$} & 3 & 0.50 & 0.48 \\
\hline & & 4 & 0.52 & 0.46 \\
\hline \multirow{4}{*}{ S.E.E } & & 1 & 0.86 & 0.85 \\
\hline & & 2 & 0.79 & 0.83 \\
\hline & & 3 & 1.12 & 1.05 \\
\hline & & 4 & 1.02 & 1.01 \\
\hline
\end{tabular}

1. Tanaka and Johnston, 2. Nourallah et al., 3. Present Study, 4. Present Modified Study. S.E.E: Standard Error of Estimated Values.

A comparison of tooth sizes shows that the mean sizes of the most permanent teeth in our study and Nourallah et al., ${ }^{(16)}$ study exceeded their counterparts in Moyers and Tanaka and Johnston ${ }^{(11)}$ (Table 5).

The increased mean widths of the relevant teeth in the present study compared with Tanaka's and Moyer's values can explain the decrease in values of constant $\mathrm{A}$ in our equations. In contrast, the value of constant B remained stable in both studies as shown in Table (4), the same results were reported in the Nourallah et al., (16) study.

A literature review revealed that there are only one recent study ${ }^{(16)}$ that used the mandibular permanent central incisors in combination with maxillary permanent first molars as an index to predict the widths of unerupted canines and premolars on Syrian population. However, there is a strong correlation between these tooth groups, as shown in Table (4). The constant $B$ values in the new analysis equations are similar to previous calculation. While constant A values differs. This is because A relates to the value of the sum widths of the index teeth which are higher in the new analysis. A remarkable reduction in the standard errors of the estimated values (Table 4) and in the percentage difference was observed, demonstrating that this new analysis is even more accurate than Tanaka and Johnston and the modified equations and this agreed with other study ${ }^{(16)}$ 
Table (5): Comparison of mean tooth sizes.

\begin{tabular}{|c|c|c|c|c|c|c|c|}
\hline \multicolumn{2}{|c|}{ Tooth } & \multirow{2}{*}{$\begin{array}{c}\text { Ballard }^{\mathbf{1 6}} \\
\mathbf{( 1 9 4 4 )}\end{array}$} & \multirow{2}{*}{$\begin{array}{c}\text { Stahle }^{16} \\
\mathbf{( 1 9 5 9 )}\end{array}$} & \multirow{2}{*}{$\begin{array}{c}\text { Black }^{16} \\
\mathbf{( 1 9 0 2 )}\end{array}$} & \multirow{2}{*}{ 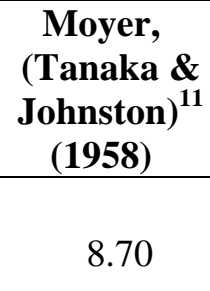 } & \multirow{2}{*}{$\begin{array}{c}\begin{array}{c}\text { Nourallah } \\
\text { et al., } \\
\text { (2001) }\end{array} \\
8.79\end{array}$} & \multirow{2}{*}{$\begin{array}{c}\text { Present } \\
\text { Study }\end{array}$} \\
\hline Max. & $\begin{array}{l}\text { Central } \\
\text { Incisor }\end{array}$ & & & & & & \\
\hline Max. & $\begin{array}{l}\text { Lateral } \\
\text { Incisor }\end{array}$ & 7.08 & 6.85 & 6.40 & 6.90 & 6.80 & -------- \\
\hline Max. & Canine & 8.00 & 7.89 & 7.60 & 7.75 & 7.87 & 7.67 \\
\hline Max. & $\begin{array}{l}\text { Ist Premo- } \\
\text { lar }\end{array}$ & 7.27 & 7.07 & 7.20 & 7.70 & 7.02 & 6.75 \\
\hline Max. & $\begin{array}{c}\text { 2nd Pre- } \\
\text { molar }\end{array}$ & 7.14 & 6.84 & 6.80 & 6.60 & 6.72 & 6.63 \\
\hline Max. & Ist molar & 10.98 & ------- & 10.70 & 10.40 & 10.46 & 10.15 \\
\hline Mand. & $\begin{array}{l}\text { Central } \\
\text { Incisor }\end{array}$ & 5.67 & 5.31 & 5.40 & 5.45 & 5.54 & 5.35 \\
\hline Mand. & $\begin{array}{l}\text { Lateral } \\
\text { Incisor }\end{array}$ & 6.26 & 6.00 & 5.90 & 5.45 & 6.07 & 5.86 \\
\hline Mand. & Canine & 7.12 & 6.89 & 6.90 & 6.75 & 6.91 & 6.79 \\
\hline Mand. & $\begin{array}{l}\text { Ist Premo- } \\
\text { lar }\end{array}$ & 7.36 & 7.20 & 6.90 & 6.85 & 7.08 & 6.92 \\
\hline Mand. & $\begin{array}{l}\text { 2nd Pre- } \\
\text { molar }\end{array}$ & 7.50 & 7.28 & 7.10 & 7.20 & 7.19 & 7.17 \\
\hline Mand. & Ist molar & 11.17 & -------- & 11.20 & 10.50 & 11.23 & ------- \\
\hline
\end{tabular}

All measurements in millimeters.

\section{CONCLUSIONS}

Modifications made on both the prediction tables and the regression equations of Tanaka and Johnston's analysis allowed a simplified approximation of the sizes of the maxillary and mandibular permanent canines and premolars to be predicted with higher accuracy in Iraqi people. The new analysis prediction tables and new regression equations based on teeth 1, 1, 6 and 6, which erupt earlier than teeth used by Tanaka and Johnston, proved even more accurate than both previous equations.

\section{REFERENCES}

1. Bernabe E, Flores-Mir C. Are the lower incisors the best predictors for the un- erupted canine and premolars sums? An analysis of a Peruvian sample. Angle Orthod. 2005; 75(2): 202-207.

2. Othman S, Harradin N. Tooth size discrepancies in an orthodontic population. Angle Orthod. 2007; 77(4): 668-674.

3. Kirschen RH, O'Higgins EA, Lee RT. The royal London space planning: an integration of space analysis and treatment planning. Part I: assessing the space required to the treatment objectives. Am J Orthod Dentofacial Orthop. 2000; 118(4): 448455.

4. Legovic M, Novosel A, Legovic A. Regression equations for determining mesiodistal crown diameters of canines 
and premolars. Angle Orthod. 2003; 73(3): 314-318.

5. Trinkman J, Mohrman G, Themm P. Vergleichende Unter suchungen der stützonen prognose. Frotschr Kieferorthop. 1990; 51: 189-194.

6. Martinelli FL, De Lima EM, Rocha R, Tirre-Araujo MS. Prediction of lower permanent canine and premolars width by correlation methods. Angle Orthod. 2005; 75(5): 805-808.

7. Rowlands P, Poling R, Slater D, Hobson $\mathrm{R}$, Steen N. Can crown-root ratio predict premolar eruption? Am J Orthod Dentofacial Orthop. 2006; 129 (3): 331-336.

8. Al-Khadra BH. Prediction of the size of unerupted canines and premolars in a Saudi Arab population. Am J Orthod Dentofacial Orthop. 1993; 104 (4): 369-372.

9. Yuen KK, Tang EL, So LL. Mixed dentition analysis for Hong kong Chinese. Angle Orthod. 1998; 68(1): 21-28.

10. Lee-chan S, Jacobson BN, Chwa KA. Mixed dentition analysis for Asian Americans. Am J Orthod Dentofacial Orthop. 1998; 113(3): 293-299.

11.Tanaka MM, Johnston LE. The prediction of the size of unerupted canines and premolars in contemporary orthodontic population. JADA. 1974; 88 (4): 798-801.

12.Jaroontham J, Godfrey K. Mixed dentition space analysis in Thai population. Eur $J$ Orthod. 2000; 22(2): 127-134.

13. Marchchioni VM, Silva MC, Araujo TM, Reis SR. Evaluation of the effectiveness of the Tanaka-Johnston method for prediction of the mesio-distal diameter of unerupted canines and premolars. Pesqui Odontol Bras. 2001; 15: 35-40.

14.Diagne F, Diop-Ba K, Ngom Pl, Mbow K. Mixed dentition analysis in Senegalese population: elaboration of prediction tables. Am J Orthod Dentofacial Orthop. 2003; 124(2): 178-183.

15. Flores-Mir C, Bernabe E, Camus C, Carhuayo MA, Major PW. Prediction of the mesio-distal canine and premolar tooth width in a sample of Peruvian adolescents. Orthod Craniofac Res. 2003; 6: 173-176.

16. Nourallah AW, Gesch D, Khordaji MN, Splieth C. New regression equations for predicting the size of unerupted canines and premolars in a contemporary population. Angle Orthod. 2002; 72(3): 216-221.

17. Hashim HA, Al-Shalan TA. Prediction of the size of unerupted permanent cuspids and bicuspids in a Saudi sample: a pilot study. J Contemp Dent Pract. 2003; 15(4): 40-53.

18. Bernabe E, Biostat C, Flores C. Appraising number and clinical significance of regression equations to predict unerupted canines and premolare. Am J Orthod Dentofacial Orthop. 2004; 126(2): 228-230.

19. Moorrees CF, Reed RB. Correlations among crown diameter of human teeth. Arch Oral Bio. 1964; 9: 685-697.

20.Bulman JS, Osborn JF. Statistics in Dentistry. London. British Dental Association. 1989; Pp: 25,44-45,60-61. 